\title{
Letters
}

Website: www.bmj.com

Email: letters@bmj.com

\section{Should women who elect to have caesarean sections pay for them?}

EDITOR-The issue of whether doctors should perform elective caesarean sections on request confronts obstetricians almost daily. ${ }^{1}$ Neither the original articles in the $B M J$ on elective caesarean section nor the correspondence that followed quantified the problem in the United Kingdom. ${ }^{12}$ tions for 978 caesarean sections performed before labour in 1976, 1986, and 1996 at the John Radcliffe Hospital in Oxford. The information was collected prospectively as part of a larger study. ${ }^{3}$ The most dramatic change has been the increase in the proportion of elective caesarean sections performed during labour at the woman's request. Of 911 caesarean sections performed during labour in 1976 and 1986 none were done at the woman's request but request.

The added morbidity and mortality associated with caesarean sections compared with vaginal delivery are clearly relevant ${ }^{2}$ but personal experience suggests that the patient's awareness of this does not reduce the demand.

The cost to the NHS for a caesarean section is not established ${ }^{2}$ but it has been calculated for the John Radcliffe Hospital at $£ 668$ (\$1069), which includes the preoperative check (£6), the operation (£188), and a mean 4.2 days in the postnatal ward (£475). ${ }^{4}$ The cost of inducing labour has been calculated at $£ 644$ for a nulliparous woman and $£ 494$ for a multiparous woman which includes the induction, intrapartum care with delivery, and a mean 2.1 days in the postnatal ward. ${ }^{4}$ Using these figures, it would be reasonable to make a small charge for those women who request a caesarean section that is not medically indicated. Since it is widely accepted that women should be allowed to life should, however, be made clear. Nuffield Department of Obstetrics and Oxford OX3 9DU doctors perform an elet col 1998;105(suppl 17): 65 . 1997;104:1068-72. be deliverable.
The table illustrates the primary indicain 1996, 6\% were done at the mother's

choose delivery by caesarean section, ${ }^{2}$ labour induction as term approaches should also be accepted despite current opposition from obstetricians and midwives. The risk of caesarean section to a woman's health and

I Z MacKenzie Reader in obstetrics and gynaecology

Gynaecology, John Radcliffe Hospital, Headington,

1 Paterson-Brown S; Amu O, Rajendran S, Bolaji II. Should doctors perform an elective caesarean section on request?

2 De Zulueta P; Norman B, Crowhurst JA, Plaat F; Stirrat GM, Dunn PM; Idama TO, Lindow SW; Van Roosmalen GM, Dunn PM; Idama TO, Lindow SW; Van Roosmalen
J;Rosenthal A; Howard RJ. Elective caesarean section on request [letters]. BMJ 1999;318:120-2. (9 January.)

3 Cooke IE, Annan B, MacKenzie IZ. Has "Changing Childbirth" increased caesarean section rates? BrJ Obstet Gynae-

4 MacKenzie IZ, Magill P, Burns E. Randomised trial of one versus two doses of prostaglandin E2 for induction of labour. II: Analysis of cost. $\mathrm{Br} J$ Obstet Gynaecol

\section{Is general practice in need of a career structure?}

\section{Current training structure has many strengths}

EDITOR-Elwyn et al's article on general practice training carries a sense of foreboding. ${ }^{1}$ The current training structure has many strengths, though increased time in general practice is undoubtedly needed; but any model suggested as an alternative has to

The Joint Committee for Postgraduate Training for General Practice has laid down criteria for training, some of which are couched in woolly terms. The aim of each criterion is to provide the very structure for training that Elwyn et al state is lacking. The problem is in the implementation of these

Primary indications for 978 caesarean sections performed at the John Radcliffe Hospital. Values are numbers (percentages)

\begin{tabular}{lccc} 
& $\mathbf{1 9 7 6}$ & $\mathbf{1 9 8 6}$ & $\mathbf{1 9 9 6}$ \\
\hline Total deliveries & 4714 & 5967 & 6337 \\
\hline Total antepartum caesarean sections: & 171 & 321 & 486 \\
\hline Previous caesarean section & $93(54)$ & $162(50)$ & $105(22)$ \\
\hline Breech presentation & $14(8)$ & $64(20)$ & $68(14)$ \\
\hline Multiple pregnancy & $2(1)$ & $13(4)$ & $19(4)$ \\
\hline Deteriorating fetal wellbeing & $10(6)$ & $13(40)$ & $29(6)$ \\
\hline Other indications & $50(29)$ & $67(21)$ & $119(24)$ \\
\hline Maternal request & $2(1)$ & $2(1)$ & $146(30)$ \\
\hline
\end{tabular}

criteria. Formative assessments, carried out throughout the three years of vocational training, should allow any problem identified to be dealt with at an early stage. Communication skills as taught by formative video recording of consultations is an integral part of general practice training. Two surveys before and after the implementation of a pilot system for summative assessment in the west of Scotland showed the practice of using three formative videos in the training year increase from $76 \%$ to $94 \% .^{23}$

The audit project is part of the "onerous requirement" to which registrars have to submit themselves. It can be carried out at any time during the three years of training, but until last year all audits were completed in general practice. As a result of 67 hospital reaccreditation visits in the west of Scotland, which produced 10 audits, it was decided that all senior house officers on the scheme should submit a completed audit cycle or a significant event analysis in each of their six month posts. In the first six months to 31 July 1998, 21 completed audit cycles were submitted, 15 of which passed summative assessment. Much of the trainer's report could similarly be devolved to the hospital component of training.

The only references relating to summative assessment in Elwyn et al's article are from two critics of the process. Much remains to be done to improve summative assessment, but it has certainly flushed out basic structural problems-particularly organisational-in many regions. If we were willing to be more honest about the current three year training structure, in both hospital and general practice, we would not need to extend it as the authors suggest.

Training should be seen as a top priority in the career structure of general practice. The three years of training undoubtedly require closer scrutiny, and a realistic training grant should reflect this.

Murray Lough Assistant director (audit) Moya Kelly Assistant director (vocational training) Stuart Murray Director of postgraduate education Department of Postgraduate Medical Education, Glasgow G12 9LX mlough@pgm.gla.ac.uk

1 Elwyn GJ, Smail SA, Edwards AGK. Is general practice in need of a career structure? BMJ 1998;317:730-3. (12 September.)

2 Campbell LM, Murray TS. Trainee assessment-a regional survey. Br J Gen Pract 1990;40:507-9.

3 Campbell LM, Murray TS. The effects of the introduction of a system of mandatory formative assessment for general practice trainees. Med Educ 1996;30:60-4. 
SHO posts are important for registrars in general practice

EDITOR-Changes in training for general practice in the United Kingdom are undoubtedly due. ${ }^{1}$ Vocational training schemes struggle to fill their posts. Taking away these posts and making general practice training entirely practice based would starve hospitals of staff but, more importantly, remove what is valuable experience for a prospective general practitioner.

Patients seen in hospital are often more sick than those whom general practitioners treat at home or in a cottage hospital. The ability to distinguish between a seriously ill child and a child who is merely upset is probably one of the most valuable lessons I learnt during my hospital paediatrics attachment. The suggestion that training should be practice based is based on a system of learning from a consultant in the outpatient department. Unless consultants can be encouraged to have special clinics with only new patients there will be little chance to go over the entire history. Furthermore, it is often the acute receiving that is most rewarding in educational terms. How would this fit into practice based training?

A further difficulty with attendance in the outpatient department is the disruption to the general practice. One of the joys of primary care is the continuity of care. This is made more difficult when occasional days have to be spent out of the surgery: one loses the sense of belonging to the practice. During my vocational training my year in practice was intensely busy, with summative assessment, the MRCGP exam, and attending other courses. In my practice, on call was on a rota of 1 night in 9 . Even with the busy practice and frequent on call, I became comfortable with general practice only after nine or 10 months of doing the job. After completing my basic three year training scheme, summative assessment, and my MRCGP exams I left the practice and undertook a six month post in casualty; I am now doing an extra six months at a second general practice, free from worry about exams and summative assessment. I also have more experience, which makes the job less daunting and more enjoyable.

Good jobs as a senior house officer are an asset to any registrar in general practice and should not be sacrificed. Additional time in practice, free from exams, summative assessment, and other more academic work, is also useful and should be achieved by extending the practice year. An experienced registrar can offer a lot to a practice.

Rob Walter GP registrar (additional six months) 29 Castle Douglas Road, Dumfries DG2 7PA rob.walter@virgin.net

1 Elwyn GJ, Smail SA, Edwards AGK. Is general practice in need of a career structure? BMJ 1998;317:730-3. (12 September.)

\section{GPs' clinical sessions should be reduced}

EDITOR-Elwyn et al rightly see poor training as an important factor in the recruitment of doctors to general practice; they show some of the problems by contrasting general practice with specialist training. ${ }^{1}$ Another important factor in recruiting and retaining general practitioners is shown by the different levels of clinical commitment in general practice and hospital medicine.

Full time general practitioners routinely spend around eight half days a week face to face with patients. Few hospital consultants spend anything like this time doing hands on clinical work, around five or six half days being typical. Undertaking five or six clinical sessions (half days) in general practice is seen as a part time option. But no one would consider calling a hospital consultant part time because he or she sees patients for "only" five or six half days a week. Both jobs carry a high level of managerial and administrative work in addition to their clinical components. It would be difficult to argue that general practice is less onerous in this respect.

I completed my vocational training in London in 1996 and am therefore a targe for many of the attempts to address the problems of recruitment to general practice in inner London. $^{2}$ A common feeling among my peers is that undertaking eight or more clinical sessions is too onerous, and for many this is a barrier to them becoming principals. This is a quite separate issue from the wish by some to work part time. Doctors emerge from vocational training with extremely high expectations of the level of care they wish to provide, which are matched by the increasingly high expectations of patients.

Providing the highest level of care is difficult when one is seeing patients during almost all working hours. Ongoing education and training are vital for all general practitioners. Involvement in practice development, undergraduate teaching, and audit and research are important to many. All of these things require time away from patients. Expecting general practitioners to fit everything that is not direct clinical contact into half a day a week is unreasonable; it is no way to produce a vibrant specialty full of highly trained and motivated doctors, which would be the best advertisement for recruitment into primary care.

Liam Smeeth General practitioner on retainer scheme Keats Group Practice, London NW3 1NR l.smeeth@ucl.ac.uk

1 Elwyn GJ, Smail SA, Edwards AG. Is general practice in need of a career structure? BMJ 1998;317:730-3. (12 September.)

2 Hayward J, Modell M. New incentives for general

practitioners in London. BMJ 1995;311:1314-1315

Training schemes after vocational training are useful and popular

EDITOR-Elwyn et al are right to question the content and appropriateness of the training of today's general practitioners. Despite the enthusiasm and commitment of both trainers and registrars in general practice, many doctors leaving vocational training seem unwilling to become principals straight away. Travelling the world, doing locums, and gaining wider life experience seem more attractive. ${ }^{2}$
Traditional training in general practice makes doctors "fit for practice" in that they become eligible to receive the necessary certification to practise as independent principals. With the burgeoning demands and complexity of contemporary general practice, however, the transition from registrar in general practice to principal looks increasingly difficult. Several schemes now exist after vocational training schemes, anticipating the sort of extra training opportunities that the authors envisage and thereby enabling doctors on the schemes to become "fit for purpose."

These schemes provide protected time for education and further training, peer group support, mentoring, and the opportunity to work in a range of practices. Adopting a creative approach allows them to tailor what they offer to doctors' individual needs. Some are primarily academic, while others are more service based. ${ }^{4}$ They offer an alternative model for training in general practice in which the learner's choices replace the inflexibility of a process dominated by the curriculum or assessment. That is why young general practitioners choose them and why they offer the pattern for the future.

Jamie Harrison General practice tutor County Durham

Tim van Zwanenberg Director of postgraduate general practice education

Postgraduate Institute for Medicine and Dentistry, University of Newcastle, Newcastle upon Tyne NE2 4AB

1 Elwyn GJ Smail SA, Edwards AGK. Is general practice in need of a career structure? BMJ 1998;317:730-3. (12 September.)

2 Vaughan C. Career choices for generation X. BMI 1995:311:525-6.

3 Harrison J, van Zwanenberg T. Bridging the gap after vocational training [career focus]. BMJ 1998;316 (classified section 20)

4 Harrison J, van Zwanenberg T. GP tomorrow. Oxford: Radcliffe Medical, 1998

5 Bonsor R, Gibbs T, Woodward R. Vocational training and beyond-listening to voices from a void. Br J Gen Pract 1998;48:915-8

\section{Future role of general practitioners must} be clarified

EDITOR-Elwyn et al's article highlights some of the problems facing educationalists involved in the development of vocational training in general practice. ${ }^{1}$ If vocational training is to change, general practitioners will need to ask some fundamental questions about the role of doctors in multidisciplinary primary care teams. There is no doubt that the government's expectations are for a different structure in primary care. ${ }^{23}$ General practitioners in primary care groups could find themselves with a role very different from that of traditional general practitioners. As hospitals get smaller, with a corresponding increase in the intensity of care, much routine management will be delegated to primary care groups.

Primary care teams will need to work within strict guidelines, creating a similar structure to that found in many health maintenance organisations in the United States. The setting up of these clinical guide- 
lines is a skilled task involving high levels of clinical knowledge as well as managerial skills to ensure implementation. ${ }^{4}$

Our experience of training nurse practitioners to masters level has shown that trained nurses can take over a considerable amount of the work previously done by general practitioners. Over the past 10 years much of the responsibility of caring for patients with chronic disease has been delegated to practice nurses, and we envisage this happening increasingly.

Most practitioners now accept that primary care in the future will be different. Vocational training will need to change to meet the new demands that the NHS places on general practitioners. Elwyn et al suggest that vocational training "should be a practice based activity, except for the occasional sojourn to the technical world of specialists." Perhaps this vision of the future is too simplistic. The general practitioner of the future may well be a clinical technocrat, and much of the work carried out in the practice may require extensive knowledge of modern technical developments. Should we therefore be looking at a more clinical approach to vocational training? Perhaps we should be encouraging vocational trainees to specialise to a high level in one particular area so that when they are working in a primary care group they can competently manage patients previously managed in hospital.

Those involved with the process of change to vocational training will need to examine the future role of general practitioners before committing trainees to a programme that may not be appropriate for their role in a clinical team.

Peter Bundred Reader in primary care P.Bundred@liverpool.ac.uk

Trevor Gibbs Director of community studies Department of Primary Care, University of Liverpool, Liverpool L69 3GB

1 Elwyn GJ, Smail SA, Edwards AGK. Is general practice in need of a career structure? BMJ 1998;317:730-3. (12 September.)

2 Secretary of State for Health. The New NHS. London: Stationery Office, 1997. (Cm 3807.)

3 NHS Executive. The new NHS. establishing primary care rective. The new Nis. establish primary car groups. London: Department of

4 Grol R, Dall ... T. J. 't Veld CTS, Rutten G, Mokkink Atuibutes of Attributes of clinical guidelices lines in general practice. observational study. $B M$ J 1998;317:858-61. (26 September.)

\section{Training in family practice in US has many strengths}

EDITOR-I agree with Elwyn et al in their assessment of vocational training and the inadequacies of the current senior house officer posts approved for "general professional training." I was surprised, however, that among their comparisons of postgraduate training in general practice they did not mention the well established system that operates successfully in the United States.

During a three year family practice residency training programme in the United States a trainee (or resident) is attached to the same family practice site for one to four sessions a week. This allows him or her to develop some continuity of care over the three years. In addition, whereas training in senior house officer rotations in the United Kingdom "is often non-existent, and certainly not oriented to general practice," in the United States time is spent rotating through specialist outpatient clinics that are relevant to family practitioners-for example, in orthopaedics, ophthalmology, and gynaecology. This is in addition to inpatient rotations in medicine, surgery, paediatrics, and obstetrics. Furthermore, protected time is allotted each week to cover an extensive didactic curriculum over the three years.

Given the constraints of a three year training programme and the demands on family practitioners in the United States to provide both outpatient and inpatient care for their patients, the residency training programme offers an efficient means of acquiring the necessary skills. I suggest that rather than looking solely within Europe for ways of improving postgraduate training in general practice, you should incorporate some of the strengths of family practice training in the United States.

Matthew J Thompson Chief resident

University of Cincinnati-Franciscan Hospital Family Practice Residency Training Program, 2446 Kipling Avenue, Cincinnati, OH 45239, USA

thompmw@email.uc.edu

1 Elwyn GJ, Smail SA, Edwards AGK. Is general practice in need of a career structure? BMJ 1998;317:730-3. (12 September.

\section{All three years of vocational training} should be based in general practice

EDITOR-The title of Elwyn et al's article asks whether a career structure is needed in general practice ${ }^{1}$; the answer must be a resounding yes. General practice is emerging as the frontline career in the new NHS. ${ }^{2}$ Preparing young doctors for a career in general practice requires an enlarging curriculum: clinical, managerial, research, and developmental issues form its nucleus.

I often find myself explaining to colleagues from around the world that this so called jewel in the crown of training in general practice requires two of the three precious years of the programme to be spent in hospital centred medicine, often in posts of dubious educational benefit for trainees. This requirement is absurd, and the absurdity gets even worse. In answer to a question asking why the situation is not changed I reply something along the lines of, "this will cause a major problem for hospitals in terms of service provision." Here lies the heart of the problem.

Until general practice is seen as a specialty in its own right and the appropriate paradigm shift occurs in our thinking we will remain stuck in believing that young doctors can become general practitioners only after some rite of passage in hospital centred initiation rituals. The comparison with arrangements for specialist training for hospital doctors is stark.

The Association of Course Organisers adopted a motion at its annual conference in June 1997 stating that "All three years of GP vocational training should be based in general practice." Action on this motion is now overdue, and we call on all parties involved in training for general practice to work together on formulating a new manifesto. It is not enough for lone voices to speak out on the matter ${ }^{4}$; the defects in the current programme need remedying.

Shake Seigel Chairman, Association of Course Organisers (http://www.aco.org.uk)

170 Main St, Alrewas, Staffordshire DE13 7ED bitty_shake@compuserve.com

1 Elwyn GJ, Smail SA, Edwards AGK. Is general practice in need of a career structure? BMJ 1998;317:730-3. (12 September.)

2 Department of Health. The new NHS; modern and dependable. London: NHS Executive, 1997.

3 Department of Health. A guide to specialist registrar training. London: NHS Executive, 1996.

4 Hasler J, Morando S, Percy D, Plant M, Smail S. Vocational training for general practice: from $\mathrm{SHO}$ rotations to general practice training programmes. London: Committee of Regional Advisers in General Practice in England, 1997.

5 Orme-Smith A, A new structure for vocational training.

Educ Gen Pract 1998:9:173-8.

\section{Effects of the Heartbeat Wales programme}

\section{Programme that originated in Finland should be adopted}

EdiToR-We agree with Ebrahim and Davey Smith that contamination of the "control" area in the Heartbeat Wales programme seems likely. ${ }^{12}$ The aetiological evidence for coronary heart disease is now well established-principally smoking, poor diet, raised cholesterol concentrations, hypertension, and poverty. ${ }^{3}$ This risk factor model helps to explain the trends within countries and the large differences between countries. ${ }^{3}$ But how can we achieve the 10 -fold lower mortality from coronary disease that is seen in Japan and France?

Ebrahim and Davey Smith suggest that, in isolation, the effectiveness of all community based interventions is low. ${ }^{2}$ Might it therefore be useful to examine the bigger picture? In Finland mortality from coronary heart disease has dropped by $73 \%$ in North Karelia and by $65 \%$ elsewhere. ${ }^{5}$ Why is this more than twice the fall in Britain, a country with similar cardiovascular epidemiology?

In Finland a comprehensive, integrated programme of prevention and treatment started in 1972 in North Karelia and extended to the rest of Finland five years later. ${ }^{5}$ The response was rapid and impressive. The components and key principles of the Finnish programme have now been refined and extended to many countries through the World Health Organisation's country-wide integrated non-communicable disease initiatives. ${ }^{5}$ The key principles include a comprehensive programme at national, regional, community, and individual levels; a medical framework covering primary prevention and a population perspective; and a social and behavioural framework..$^{5}$

Could this programme be applied to the United Kingdom? Its autocratic imposition would be neither welcome nor effective, but after decades of resistance a growing professional and political consensus may now be 
seen in the public health green papers. Most now recognise that the effective prevention of future disease requires comprehensive integrated multiagency programmes addressing poverty and the wider determinants of ill health, including employment, food, and transport. ${ }^{235}$ This implies programmes that are multiagency, multidisciplinary, participatory, democratic, flexible, and well resourced. ${ }^{15}$ Adequate monitoring and evaluation will be essential. ${ }^{13-5}$

Past and current prevention schemes in the United Kingdom have achieved much. From the international perspective, however, they probably seem uncoordinated and half hearted, and also costly in terms of future increases in the burden of entirely preventable cardiovascular disease. Does it have to be like this? Given the growing consensus among the stake holders, is the time now right for effective action? Might political will translate into adequate resources? If so, could this promote a model for the first of a series of national public health policies in Britain?

Simon Capewell Senior lecturer

James McEwen Head of department

Department of Public Health, University of

Glasgow, Glasgow G12 8RZ

CAPEWELLs@compuserve.com

James Dunbar General practitioner

Downfield Surgery, Dundee DD3 8NE

Pekka Puska Head of department

KTL National Public Health Institute, FIN 00300, Helsinki, Finland

1 Tudor-Smith C, Nutbeam D, Moore L, Catford J. Effects of the Heartbeat Wales programme over five years on behavioural risks for cardiovascular disease: quasi-experimental comparison of results from Wales and a matched reference area. $B M J$ 1998;316:818-22.

2 Ebrahim S, Davey Smith G. Effects of the Heartbeat Wales programme. BMJ 1998;317:886. (26 September.)

3 Tunstall-Pedoe H. Cardiovascular diseases. Oxford textbook of public health. Oxford: Oxford University Press, 1997.

4 Capewell S, Morrison CE, McMurray JJV. Contribution of Capewell S, Morrison CE, McMurray JJV. Contribution of modern cardiovascular treatment to the decline in coronary heart disease mortality in Scotland between 1975 and
1994. Epidemiol Community Health 1997;51:583.

5 World Health Organisation. CINDI: country-wide integrated non-communicable disease initiatives. Protocol and guidelines for monitoring and evaluation; process of policy development and implementation. Copenhagen WHO, 1997.

\section{Authors' reply to letters published in September}

EdITOR-In effect, Ebrahim and Davey Smith's letter about our paper ${ }^{1}$ summarises the lessons that might be extracted from evaluations of the Heartbeat Wales programme. When the project was conceived it was based on the best available evidence concerning causality and intervention, influenced by Rose's population strategy of prevention $^{2}$ and concepts in the Ottawa Charter on Health Promotion. With the benefit of advances in knowledge and a different political climate now, population interventions in the United Kingdom today would be better focused on powerful social and economic influences on health and directed more towards influencing populations at greatest risk.

The authors describe the findings as negative. We avoided this simplistic conclusion because we do not know the extent to which the findings represent "success" or "failure." The data show consistent progress in Wales in reducing behavioural risk during the period of the intervention. They also indicate similar change in a reference area. The authors concede that contamination of the reference area is a feasible explanation of the failure to show a net effect between Wales and the reference area but dismiss this as the likely explanation, failing to take adequate account of a paper providing evidence of contamination. ${ }^{3}$ This evidence is not provided in the other community health promotion programmes that they refer to. Interventions such as the Heartbeat Wales programme are difficult to evaluate with conventional experimental designs; we need to develop evaluation techniques that combine the strengths of quantitative and qualitative research methods, especially to examine the effects of the social and economic interventions that they advocate.

Tudor-Hart's letter, in which he discusses the use of market research companies to do "epidemiology on the cheap," betrays prejudice against the widely used practice of employing professional companies for cost effective data collection in community wide studies. The results presented in the paper indicate that some of the effects of non-response were accounted for in the weighting of data. The paper also cites two follow up studies of non-responders, which indicate that the likely bias is far less than commonly assumed. ${ }^{45}$ This information seems to have been overlooked.

Harvey's letter seems motivated by a deep sense of funding injustice but does not give a credible case for abandoning efforts to promote health through primary health care and other channels. Those of us working in health promotion are acutely conscious of the need to operate more effectively in deciding what interventions to promote. The health promotion field of the Cochrane Collaboration shows the efforts being made to develop and apply evidence in health promotion.

Don Nutbeam Professor of public health Department of Public Health and Community Medicine, University of Sydney, NSW 2006 , Australia

Laurence Moore Lecturer in health services research University of Bristol, Department of Social

Medicine, Bristol BS8 2PR

Laurence.Moore@bristol.ac.uk

1 Effects of the Heartbeat Wales programme [letters]. BM] 1998:317:886-7. (26 September.)

2 Rose G. Sick individuals and sick populations. Int $J$ Epidemiol 1985;14:32-8.

3 Nutbeam D, Smith C, Murphy S, Catford J. Maintainin evaluation designs in long term community-based health promotion programs: the Heartbeat Wales case study. Epidemiol Community Health 1993;47:127-33.

4 Pullen E, Nutbeam D, Moore L. Demographic characteristics and health behaviours of consenters to medical examination. Results from the Welsh heart health survey. Epidemiol Community Health 1992;46:455-9.

5 Smith C, Nutbeam D. Assessing non-response bias: a case study from the 1985 Welsh heart health survey Health Educ Res 1990:5.381-6.

\section{The Di Bella multitherapy trial}

Randomised controlled trials may not always be absolutely needed

EdiToR-We disagree with Müllner's editorial $^{1}$ as it took a very narrow perspective on a case in which attention should have been paid to the relations between general methodological principles of cancer trials and the social context in which the Di Bella story took place. ${ }^{2}$

The editorial might give the (wrong) impression that the $\mathrm{Di}$ Bella trial ${ }^{3}$ was inadequate and could not show the lack of antitumour activity of Di Bella's multitherapy. In 1982 an editorial in the New England Journal of Medicine accompanied the publication of a phase II study of the US National Cancer Institute on another anticancer "miracle" treatment named laetrile. This said that the study "closed the book on laetrile." Interestingly, that study adopted the same non-randomised design (and the same negative results) as the Italian study.

Have general methodological principles of clinical research in oncology changed so dramatically since then? We do not think so and suspect that the editorial indicates limited familiarity with phase II trials in oncology. Too much familiarity with a given research field may lead to blindness concerning its limitations, ${ }^{5}$ and the view is perfectly legitimate that current standards of phase II oncology trials should be abandoned. But why was not this the main theme of Müllner's editorial? Why did all criticism exclusively target the Di Bella trial?

To illustrate possible approaches to similar cases in the future a more general discussion of pros and cons of randomised versus non-randomised studies in similar cases (in terms of risk of bias, costs, time needed to get an answer, likelihood that such an answer will be accepted, acceptability, or randomisation in situations characterised by high social and political pressure, etc.) would have been useful. Is strict adherence to the dogma of randomisation always the best solution in phase II trials, when what matters is to determine whether a new drug or regimen has sufficient biological activity to warrant more extensive, costly, and time consuming studies?

Maybe a commentary would have served the purpose better. Are we sure that insisting that randomised controlled trials are always absolutely needed for a perfect study will not end up, in the long run, doing more harm than good to the future of evidence based health care? We hope that the $B M J$ will promote a discussion around these topics.

Alessandro Liberati Professor of biostatistics Università di Modena, Centro per la Valutazione della Efficacia della Assistenza Sanitaria Modena, Italy

Email alesslib@tin.it

Nicola Magrini Unit head

Centro per la Valutazione della Efficacia della Assistenza Sanitaria (CeVEAS) Modena, Italy

Lucio Patoia Unit head

CeVEAS Modena, Unità di Medicina Interna e Scienze Oncologiche, Perugia, Italy

Luigi Pagliaro Professor of internal medicine Divisione di Medicina Interna, Università di Palermo, Palermo, Italy

1 Müllner M. Di Bella's therapy: the last word? $B M J$ 1999;318:209-10. (23 January.)

2 Turone F. Italy starts trials for controversial cancer treatment. BMJ 1998;316:327. 
3 Italian Study Group for the Di Bella Multitherapy Trial. Evaluation of an unconventional cancer treatment (the D Bella multitherapy): results of phase II trials in Italy. $B M$ J 1999;318:224-8. (23 January.)

4 Relman AS. Closing the book on laetrile. $N$ Engl J Med 1982;299:236

5 Simonetti RG, Liberati A, Angiolini C, Pagliaro L Treatment of hepatocellular carcinoma: a systematic review of randomized controlled trials. Ann Oncol 1997;8:117-36.

\section{Criticism ignores standard methodology} of cancer treatments

EDITOR-In his editorial on the trials conducted to evaluate the anticancer treatment known as Di Bella multitherapy, ${ }^{1}$ Müllner argues that "the design of the studies is flawed" and that "the researchers should have conducted randomised controlled trials." ${ }^{2}$ Müllner's criticism seems to ignore the standard methodology in the development of cancer treatments. ${ }^{3}$ This requires that the activity of a treatment be ascertained by means of phase II trials, before randomised phase III trials can even be considered. The aim of phase II trials is to distinguish between drugs with promising activity warranting further trials, and drugs for which further trials on human subjects are not justified. Their methodology responds to the ethical imperative of minimising the number of patients exposed to useless and potentially harmful treatments as well as the time needed to identify potentially useful treatments.

In phase II trials of cancer treatments, randomised control groups are usually not needed because the end point most often used is "objective response" (defined on the basis of the observed reduction of tumour size), that seldom occurs spontaneously. Blinding is never used in cancer trials, mainly because of the obvious toxicity of most cancer treatments. Indeed, it would have been impossible to conduct a randomised trial of Di Bella multitherapy in Italy. Given the wide media coverage and the public's great expectations of high efficacy of this treatment, and in the face of some 2000 free Di Bella treatments ordered by the courts, the enrolment of hundreds of patients, accepting to be assigned at random to a treatment that might not have been Di Bella multitherapy, was inconceivable. For all of these scientific, ethical, and practical reasons, after a thorough discussion, the Italian National Oncology Committee recommended the immediate start of phase II trials.

In the process of evaluating anticancer treatments, "uncontrolled" phase II trials (yet under controlled conditions) are far from being "studies of weak design" and provide direct, objective, verifiable, and rapid evaluations. This represents the real interest of patients. In past decades, many anticancer treatments with a preclinical evidence of activity or a therapeutic rationale much stronger than those of Di Bella multitherapy were excluded from further trials (and from clinical use) solely on the basis of the results of "uncontrolled" phase II trials that showed insufficient activity. In any case, the claim that in studies on Di Bella multitherapy "we do not know whether controls would have done better or worse" contrasts with the observed response rate $(<1 \%)$ and poor survival. ${ }^{1}$ We consider these findings sound enough to prevent vulnerable cancer patients and desperate relatives from pursuing hopeless treatments.

R Raschetti Head of pharmacoepidemiology unit D Greco Head of epidemipology department

F Menniti-Ippolito Biostatistician

S Spila-Alegiani Biostatistician

G Traversa Epidemiologist

G Benagiano Director

Istituto Superiore di Sanità, I-00161 Rome, Italy

P Bruzzi Head of clinical epidemiology unit

Istituto Nazionale Ricerca sul Cancro, I-16132

Genova, Italy

on behalf of the Editorial Committee of the Italian

Study Group for the Di Bella Multitherapy Trials

1 Italian Study Group for the Di Bella Multitherapy Trials Evaluation of an unconventional cancer treatment (the Di Bella Multitherapy): results of phase II trials in Italy. $B M J$ Bella Multitherapy): results of

Müllner M. Di Bella's therapy: the last word? $B M J$ 1999:318.208-9. Bella's therap

3 De Vita VT, Hellman S, Rosenberg SA. Cancer: principles and practice of oncology. 5th ed. New York: Lippincott-Raven,

\section{Reply from author and statistical adviser}

EDITOR-It is unfortunate that my editorial has been misinterpreted as suggesting that the trial of the Di Bella therapy was "useless." The $B M J$ does not publish a paper if its results are believed to be invalid. It does publish papers where, although the evidence is not up to the standards that might be desirable, the evidence is the best available on a topic of importance. Most readers may well be able to decide for themselves whether the present results give strong enough evidence against the claims of the Di Bella multitherapy. In our opinion, the trial provided good evidence that Di Bella's therapy did not match up to the unreasonable claims made for it-Liberati et $\mathrm{al}^{1}$ quote Di Bella as claiming that he can cure $100 \%$ of cancers. We believe, however, that this study was not of the best possible scientific quality, although some readers adopt a more drastic point of view. ${ }^{2}$ It is a matter of opinion as to whether the study was a phase II trial in the usual sense or not. It can be argued that this therapy was not in the early stage of a screening process but that a confirmatory trial was required. There certainly are randomised and controlled phase II trials, even in cancer, although we agree that they are frequently uncontrolled in that clinical area. It is understandable that, in the emotional and political situation like the one in Italy an uncontrolled study was the most or only practical option available to test $\mathrm{Di}$ Bella's therapy. This does not mean that in scientific terms an uncontrolled study would always provide the best answer. Raschetti's response ${ }^{3}$ implies that the current practice of uncontrolled phase II studies cannot be questioned. Liberati et al take a more liberal view and state that it is legitimate to challenge present methodology, but the editorial did not make a general statement. Did it miss this opportunity of a more general debate of advantages and disadvantages of randomised controlled trials in similar settings? We think not: these issues were addressed as part of the editorial, and the present discussion is a good example of an evolving debate. The $B M J$ web- site, allowing rapid response and flexibility, is a suitable platform, and the forum is now open for discussion. It is time to rethink: the published last word is gone.

Marcus Müllner Editorial registrar

Stephen J W Evans Statistical adviser

$B M J$, London WC1H 9JR

1 Liberati A, Magrini N, Patoia L, Pagliaro L. Missing the forest while looking at the tree. $e B M J$ www.bmj.com/cgi/ eletters/318/718/208\#EL3 [16 Feb 1999].

2 Reyes JL. Compared to what? $e B M J$ www.bmj.com/cgi/ eletters/318/7178/208\#EL1 [22 January 1999].

3 Raschetti R, Bruzzi P, Greco D, Maggini M, MennitiIppolito F, Spila-Alegiani S, et al. We totally disagree with Müllner's view. $e B M J$ www.bmj.com/cgi/eletters/318/ 7178/208\#EL2 [8 Feb 1999].

\section{Randomised controlled trials are important}

EDITOR-Cranberg's arguments against controlled trials and in favour of historical controls supported by data on matching for known risk factors are seriously flawed. ${ }^{1}$ There are at least four fallacies.

Firstly, the matching procedures can be valid only for known risk factors, whereas randomisation minimises imbalance of unknown factors. Secondly, the use of historical controls introduces the problem of secular trends with no way of eliminating the associated bias. Thirdly, there will always be different levels of completeness of data acquisition when routine case notes are compared with data from a prospective trial. Fourthly, the proposition that patients receiving placebo in a controlled trial suffer from being deprived of the newest treatment is ridiculous. If evidence shows that the new treatment is better than placebo the trial will not be taking place-Peto's principle of uncertainty ensures this. If there is no evidence of superiority but good reason for hope this has to be balanced against the possibility that the new treatment causes adverse effects. Luddites deserve to be ignored.

Geoff Venning Consultant in pharmaceutical medicine

Pharmaceutical Research Services, 14 Lucas Road, High Wycombe, Buckinghamshire HP13 6QG

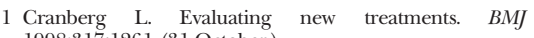

\section{Height and risk of cancer}

\section{Survival selection bias should have been} ruled out

EDITOR-In two separate cohort studies Gunnell et $\mathrm{al}^{1}$ and Davey Smith et $\mathrm{al}^{2}$ found an association between height and nonsmoking related cancers. An accompanying editorial indicates that causality for this association is supported by studies in animals. ${ }^{3}$ None of the articles, however, examines the possibility of bias from survival selection in the cohort studies.

Cancer and heart disease are the main causes of death in old age but the mean age of death for heart disease is younger than for cancer. Heart disease is strongly 
associated with smoking and also with short stature. Is it possible that there is selective survival of taller people because shorter people die earlier from heart disease? This hypothesis is strengthened by the lack of association with smoking related cancers: smoking would be expected to cause heart disease first.

A test of this hypothesis would be to compare at the same mean age the heights of people with heart disease with the heights of people who had died from cancer. Did the referee ask for this? The two papers would be strengthened if the issue could be addressed.

Mark McCarthy Professor of public health Department of Epidemiology and Public Health, University College London, London WC1E 6BT m.mccarthy@ucl.ac.uk

1 Gunnell DJ, Davey Smith G, Holly JMP, Frankel S. Leg length and risk of cancer in the Boyd Orr cohort. BMJ 1998;317:1350-1. (14 November)

2 Davey Smith G, Shipley M, Leon DA. Height and mortality from cancer among men: prospective observational study from cancer among men: prospective ob

Albanes D. Height, early energy intake, and cancer. $B M J$ 1998:317:1331-2. (14 November.)

\section{Authors' reply}

EDITOR-McCarthy raises an interesting point about our studies-namely, that associations between height and cancer arise as a result of the selective survival of taller people who, since the risk from cancer increases with age, are at a greater risk of dying from cancer. He implies that this possibility could be tested by making comparisons within narrow age groups. This is precisely what was done in our analyses. In Cox proportional hazards models the relative hazard of death at a particular point in time is based on a comparison of the characteristics of the individual who died with the characteristics of those who are still alive at that point in time. Thus, our estimates of the strength of the association between mortality from cancer and height cannot be biased by selective survival.

David J Gunnell Senior lecturer in epidemiology and public health medicine

George Davey Smith Professor of clinical epidemiology

Jeff M P Holly Professor of clinical sciences

Stephen Frankel Professor of epidemiology and public health medicine

University of Bristol, Bristol BS8 2PR

Martin Shipley Senior lecturer in medical statistics Department of Epidemiology and Public Health, University College London, London WC1E 6BT

David A Leon Reader in epidemiology

Department of Epidemiology and Population

Health, London School of Hygiene and Tropical Medicine, London WC1E 7HT

\section{Practical problems in recruiting patients with schizophrenia into randomised controlled trials}

EDITOR-Thornley and Adams surveyed the content and quality of trials relating to the care of those with schizophrenia. ${ }^{1}$ They found that studies were of short duration (only 19\% with six months of follow up), had few patients (mean number 65), and rarely community based (19\%). They concluded that "large studies, of long duration ... are needed," but they did not discuss the possible reasons for these findings.

We are currently undertaking a community based randomised controlled trial to evaluate the effects of a patient held medical record for people with schizophrenia. Power calculations suggest that we need to recruit 100 patients into each arm of the trial $(\alpha=0.05$, power $=90 \%)$ to show a clinically meaningful effect on satisfaction with health care $^{2}$ and mental health status. ${ }^{3}$

As we had anticipated, during the first 12 months of this three year trial we encountered several practical problems affecting recruitment. Potential participants were approached through the community based mental health teams. Substantial variations in working policy and practice between adjacent teams required access to team members and patients to be individually negotiated with the six teams in the mental health trust. This was logistically complicated and extremely time consuming. The positive and negative symptoms of schizophrenia affected patient recruitment. Many of the people under the care of the outreach teams were difficult to track, and at least two home visits were required to make initial contact. Over $30 \%$ of potential participants declined to take part in the trial; people with predominantly positive symptoms were suspicious of our motives while those with negative symptoms were unmotivated to take part. Ensuring fully informed consent may also be more time consuming with such potentially vulnerable people than with other groups of patients. Participants could have been recruited through primary care, but evidence suggests that professional stigmatisation and the negative views that some general practitioners hold about people with schizophrenia would simply create a different set of recruitment problems. ${ }^{4}$

None of the practical problems described above are exclusive to people with schizophrenia, but in combination they may help to explain the lack of large randomised controlled trials called for in Thornley and Adam's paper. We have recruited 130 people into our trial during the past 12 months, a feat that owes much to the enthusiasm of key workers in each mental health team.

Helen Lester Sheldon research fellow

H.E.Lester@bham.ac.uk

Sue Wilson Research fellow

Department of General Practice, University of Birmingham Medical School, Birmingham B15 2TT

1 Thornley B, Adams C. Content and quality of 2000 controlled trials in schizophrenia over 50 years. $B M$ 1998;317:1181-4. (31 October.)

2 Ruggeri M, Dall'Agnola R. The development and use of the Verona expectations for care scale and the Verona satisfaction scale for measuring expectations and satisfaction with community based psychiatric services in patients, relatives and professionals. Psychol Med 1993;23:511-23.

3 Krawiecka M, Goldberg V, Vaughn M. A standardised psychiatric assessment scale for rating chronic psychotic patients. Acta Psychiatr Scand 1977;55:299-308.

\section{Employing staff on long term contracts is important for RGTs}

EDITOR-Medical professionals and funding agencies do not seem to recognise the importance of a trained, experienced, multidisciplinary team in the setting up and coordination of a multicentre clinical trial. ${ }^{1}$ They also do not seem to recognise the role that such teams have in maintaining enthusiasm among medical staff throughout the often long periods of recruitment and follow up.

The cost of employing a dedicated trial team is poorly appreciated. It is essential to train and maintain staff to provide the necessary skill. Although training is available for statisticians and programmers, training facilities for trial coordination staff are limited. Career plans for all staff are often unstructured, if they exist at all.

The time taken to maintain enthusiasm in centres, to visit centres throughout the trial, to monitor recruitment, and to identify methods to improve recruitment is often underestimated. A well run trial also involves considerable data handling, including the chasing, checking, and monitoring of trial data to improve their accuracy and completeness. As Farrell points out, a customised computer program is essential in clinical trials. ${ }^{1}$ However, the time and cost of developing trial specific databases and purchasing computer hardware, software, and systems support are often underestimated.

Employing staff on long term contracts ensures job security, motivation, and the opportunity to build on the skill and knowledge of existing staff. This, however, usually depends on the provision of core funding, which is critical to maintaining a pool of experienced and trained employees.

We encourage the development of recognised training courses and career development for trial staff; urge funding bodies to recognise the importance of funding experienced core staff, who are critical to successful completion of trials and data collection; and encourage units to share their experience of data management and trial procedures using both current and new technologies. The importance of core funding to provide training and financial resources for experienced core staff in multicentre trials units must be recognised; it is the only sensible way of providing cost effective, high quality multicentre research that will answer the nation's main health questions.

Maxine Stead Quality assurance manager mls@yco.leeds.ac.uk

Su Mason Joint head of unit

Trish Shevlin Senior medical statistician

Julia Brown Joint head of unit

Northern and Yorkshire Clinical Trials and Research Unit, Leeds LS16 6QB

1 Farrell B. Efficient management of randomised controlled trials: nature or nurture. BMJ 1998;317:1236-9. (31 October.) 


\section{Bullied children are picked on for their vulnerability}

EDITOR-All school doctors and nurses in the South Downs Health Trust were asked to record, over two months in 1997, details of health contacts with children aged 8-14 in which bullying was assessed as an important factor affecting the health consultation. Staff (eight doctors, 14 nurses) logged 97 contacts. As in Salmon et al's study, ${ }^{1}$ half the children were aged 11-12 and attending secondary schools. Nearly two thirds of the children in the trust's study were girls; a "drop in" service at a school nurse clinic was a common mode of contact, and evidently this service was used more readily by the girls.

The vulnerability of this bullied group was particularly striking. Fifteen had recognised learning difficulties, 30 had physical disability (including cleft palate, hemiplegia, a hearing aid, spinal deformity), and 31 were experiencing a family crisis or family distress or were actually neglected. For many, the bullying was of recent onset, but one in seven complained of long term bullying. The children were followed up after six months; other support services (including social services, counselling, special school) had been arranged for 25 , but most were supported by school health staff. Indeed, one in seven had longstanding difficulties and already had a programme of continuing support from school health staff.

School health staff are more likely to see bullied children with pre-existing problems, as these children would already be familiar with their school nurses and doctors and therefore able to turn to them in their distress. But it is a sad comment on group behaviours that it is anxious, depressed pupils with poor self esteem, who already have much to cope with in terms of physical, personal, or social disadvantage, who become the victims of bullies. We all need to take responsibility and protect where we can.

Sonya Leff Consultant community paediatrician South Downs Health NHS Trust, Brighton BN2 3EW

jkbaksi@zauber.u-net.com

1 Salmon G, James A, Smith DM. Bullying in schools: self reported anxiety, depression, and self-esteem in secondary school children. BMJ 1998;317:924-5. (3 October.)

\section{More financial resources must be provided for multidrug resistant $\mathrm{TB}$}

EDITOR-Drobniewski endorsed the need for the rational use of rapid diagnostic tools in the diagnosis of multidrug resistant tuberculosis. ${ }^{1}$ This model of rapid culture and sensitivity testing should become the rule rather than being the exception as at present. Only by making the earliest possible diagnosis can we achieve optimum management.

In England and Wales in 1997 there were 5859 notifications of tuberculosis and 447 deaths from the disease; isolates of multidrug resistant tuberculosis reported to the Communicable Disease Surveillance
Centre have risen from 18 to 43 a year over the past five years (personal communication, Public Health Laboratory Service, Colindale). Although the incidence of multidrug resistant tuberculosis is presently only $1.1 \%$ in England and Wales, ${ }^{2}$ in some countries (for example, Latvia) it has reached 22\%.

It is important to recognise that many issues related to resources, in addition to laboratory diagnosis, arise in cases of multidrug resistant tuberculosis:

- Negative-pressure isolation is essential (ideally with continuous monitoring);

- Effective but expensive masks are necessary;

- Patients must be admitted to hospital and remain there until three negative smears are obtained over 14 days $^{34}$;

- Expensive multiple treatment is recommended;

- Admission to hospital may be for several months, and the patient's mental state and physical fitness must be cared for in addition to his or her clinical status;

- Directly observed therapy (DOT) is expensive but recommended. ${ }^{3}$ Currently no established structure exists for coordinating and funding it, even though it is considered to be the most effective means of reducing the incidence of tuberculosis. ${ }^{5}$

Facilities for safely managing multidrug resistant tuberculosis are limited. In North Trent, for example, the regional department of infection and tropical medicine is the only unit meeting the recommended criteria. In 1998 we looked after two patients with confirmed multidrug resistant tuberculosis and several others who were potentially infected. If patients are to be managed according to the guidelines, sufficient financial resources to enable expansion of existing facilities to accommodate them (supported by nurses and other healthcare professionals) must be made available.

We support Drobniewski's proposal for more rapid diagnosis, but this is only one issue in relation to tuberculosis. Whether the forthcoming restrictions on postal transport of specimens will encourage the development of such facilities on a subregional basis is another debate. Failure to tackle multidrug resistant tuberculosis now may cost dear in the future.

Matthias L Schmid Specialist registrar in infectious diseases

Michael W McKendrick Consultant physician

Stephen T Green Consultant physician

North Trent Department of Infection and Tropical

Medicine, Royal Hallamshire Hospital, Sheffield S10 2JF

Matthias.Schmid@csuh-tr.trent.nhs.uk

Elisabeth J Ridgway Consultant microbiologist Department of Microbiology, Royal Hallamshire Hospital

\footnotetext{
1 Drobniewski FA. Diagnosing multidrug resistant tuberculosis in Britain. BMJ 1998;317:1263-4. (7 November.)

2 Pablos-Mendez A, Raviglione MC, Laszlo A, Binkin N, Rieder HL, Bustreo F, et al. Global surveillance for antituberculosis-drug resistance, 1994-1997. N Engl J Med 1998;338:1641-9.

3 Joint Tuberculosis Committee of the British Thoracic Society Chemotherapy and management of tuberculosis in the United Kingdom: recommendations. Thorax 1998:53:536-48.

Interdepartmental Working Group on Tuberculosis. The prevention and control of tuberculosis in the United Kingdom. 1
}

HIV-related tuberculosis; 2: Drug-resistant, including multiple drug-resistant, tuberculosis. London: Department of Health and Welsh Office, 1998.

5 Bishai WR, Graham NMH, Harrington S, Pope DS, Hooper N, Stemborski J, et al. Molecular and geographic patterns of tuberculosis transmission after 15 years of directly observed therapy.JAMA 1998;280:1679-84.

\section{Some growth promoters in animals do confer antimicrobial resistance in humans}

EDITOR-In his editorial on the veterinary perspective of antimicrobial resistance McKellar says that in the United Kingdom only antimicrobials that are not used in human medicine and those which do not select for cross resistance with antimicrobials used in humans are available for performance enhancement. ${ }^{1}$

In fact, tylosin and spiramycin confer cross resistance to the macrolide erythromycin, which is an important antimicrobial drug for humans. In 1969 the Swann committee recommended that tylosin should not be available as a growth promoter. ${ }^{2}$ As a consequence of the widespread use of spiramycin and tylosin for growth promotion as well as for treatment of animal diseases, macrolide resistance is prevalent in Campylobacter spp, which are important zoonotic bacteria transferred from animals to humans through the food chain.

As McKellar says, virginiamycin confers cross resistance to streptogramins used in human medicine. ${ }^{3}$ This was the background behind the ban on using virginiamycin as a growth promoter in Denmark from January 1998. However, this agent is still available in the United Kingdom. Furthermore, a recent study showed cross resistance between the growth promoter avilamycin and everninomycin (SCH 27899), a new drug for treating multiresistant infections in humans.

In conclusion, several of the currently approved and most widely used growth promoters confer cross resistance to antimicrobial agents used in treating humans.

K B Pedersen Director

Danish Veterinary Laboratory, Bülowsvej 27, DK-1790 Copenhagen, Denmark

kbp@svs.dk

1 McKellar QA. Antimicrobial resistance: a veterinary perspective. BMJ 1998;317:610-1. (5 September.)

2 Swann MM. Joint Committee on the use of Antibiotics in Animal Husbandry and Veterinary Medicine. London: HMSO, 1969. 3 Welton LA, Thal LA, Perri MB, Donabedian S, McMahon J, Chow JW, Zervos, MJ. Antimicrobial resistance in enterococci isolated from turkey flocks fed virginiamycin Antimicrob Agents Chemother 1998;42:705-8.

4 Aarestrup FM. Association between decreased susceptibility to a new antibiotic for treatment of human diseases, ity to a new antibiotic for treatment of human diseases, eveninonycin (SCH 27899), an

\section{Hyperbaric oxygen therapy}

\section{Combination with radiotherapy in cancer} is of proved benefit but rarely used

EDITOR-Leach et al discuss various clinical applications of hyperbaric oxygen therapy. ${ }^{1}$ They conclude that the use of hyperbaric 
oxygen should be evidence based, but their article omits an important and much researched clinical use-combined radiotherapy and hyperbaric oxygen in patients with cancer.

Hyperbaric oxygen was first used 50 years ago to increase cellular oxygen delivery and thus overcome hypoxia as a cause of tumour radioresistance. The Medical Research Council coordinated several large multicentre trials. Significant benefit was found in both locoregional tumour control and survival in head and neck cancer ${ }^{2}$ and carcinoma of the uterine cervix. ${ }^{3}$ A meta-analysis of combined hyperbaric oxygen and radiotherapy reviewed 19 trials in tumours at various sites with a total of 2488 patients. ${ }^{4}$ Locoregional control with the combined modality was $62 \%$, versus 53\% with radiotherapy alone $(\mathrm{P}<0.0001)$. Subgroup analysis showed that the greatest improvement in local control and survival occurred in head and neck cancer.

This scientifically proved application of hyperbaric oxygen is now unused. It was initially hoped that chemical radiosensitisers would substitute for hyperbaric oxygen and so simplify treatment, because animal studies had generated considerable optimism; clinical trials, however, showed only marginal therapeutic gain.

Other evidence based developments in radiotherapy have not been implemented. Recent trials of altered radiotherapy fractionation have shown increased local control and survival in some tumours. ${ }^{5}$ The head and neck hyperfractionation trial of the European Organisation for Research and Treatment of Cancer showed a $19 \%$ absolute $(47.5 \%$ relative) increase in local control and consequent increase in survival. In non-small cell lung cancer a 9\% absolute improvement in survival was obtained with continuous hyperfractionated accelerated radiotherapy.

These strategies are largely neglected in the United Kingdom because of a lack of radiotherapy resources. The Faculty of Clinical Oncology's report on radiotherapy in 1992-7 shows large inequalities in service provision, with unacceptable delays before radiotherapy is started. To provide an acceptable minimum of four linear accelerators per million population, capital investment of $£ 50$ million a year for five years is required, with commitment to the revenue cost of trained staff. This should be a stated target of the NHS modernisation fund. Radiotherapy is the most important nonsurgical modality in the curative treatment of cancer, yet it is underused in the United Kingdom because of a lack of resources. At present, evidence based practice in radiotherapy is unachievable.

Charlotte Coles Specialist registrar in clinical oncology

Michael Williams Clinical director in oncology Neil Burnet Honorary consultant in oncology Addenbrooke's Hospital, Oncology Centre, Cambridge CB2 2QQ

joncha7069@aol.com
1 Leach RM, Rees PJ, Wilmshurst P. ABC of oxygen. Hyper baric oxygen therapy. $B M J$ J 1998;317:1140-3. (24 October.) 2 Henk JM, Kunkler PB, Smith CW. Radiotherapy and hyperbaric oxygen in head and neck cancer. Final repor of first controlled clinical trial. Lancet 1977;ii:101-3.

3 Watson ER, Halnan RE, Dische S, SaundersMI, Cade IS, McEwen JB, et al. Hyperbaric oxygen and radiotherapy: Medical Research Council trial in carcinoma of the cervix. Br J Radiol 1978;51:879-87.

4 Horsman MR, Overgaard J. The oxygen effect. Basic clinical radiobiology 2nd ed London: Are oxygen effect

5 Benson RJ. Burnet NG. Altered redion thery fractionaBenson RJ, Burnet NG. Altered radiotherapy fractionation: an opportu
1998; $10: 150-4$

\section{Complication rates are much lower than} authors suggest

EDITOR-We would be interested to know where Leach et al obtained their figures for complication rates of hyperbaric oxygen therapy ${ }^{1}$; our practice and that of others suggest that they are pessimistic.

Our unit provides over 2700 treatments with hyperbaric oxygen in about 250 patients each year for a range of indications, including problem wounds, decompression illness, and carbon monoxide poisoning. According to Leach et al, we should expect two to five patients with severe central neurological symptoms and 38 patients with symptomatic barotrauma or pulmonary symptoms each year. In fact, during 1997 one patient had an oxygen toxic fit, 18 had symptomatic barotrauma, and one had symptoms of severe pulmonary toxicity. Over the past three years the incidence of central neurological toxicity has been $0.5 \%$ (three patients) and of symptomatic barotrauma $7 \%$ (49 patients).

We accept that many patients have minor measurable changes in respiratory function, but these are rarely symptomatic and not clinically important. A report of the international hyperbaric incident monitoring study running from the Royal Adelaide Hospital suggests figures of $<1 \%$ (seven patients) for neurological toxicity and $<10 \%$ (21 patients) for barotrauma overall. ${ }^{2}$ Others have produced comparable figures. $^{34}$ Patients are unlikely to develop decompression illness after hyperbaric oxygen therapy (as suggested by Leach et al) unless given air for prolonged periods. To our knowledge this has never been reported, although it is certainly a risk for staff breathing air.

Fire is the most common fatal complication. Over the past 20 years, with millions of compressions in clinical hyperbaric chambers, 52 deaths have been reported. ${ }^{5}$ Almost all were preventable; 35 were in one country and due to inadequate precautions. In particular, 10 incidents resulting in 20 deaths occurred when banned substances (including lighted cigarettes) were taken into the chamber. Many treatment modalities and drugs could benefit from a safety record as good as that for modern hyperbaric medicine.

Safety figures are meaningless in the absence of therapeutic benefit, and evidence based admission and discharge criteria are essential for decision making. We strive to achieve evidence based practice but at present must rely on relatively low levels of evidence for many clinical decisions.

Barbara E Trytko Staff specialist, intensive care and hyperbaric medicine

Mike Bennett Director

Department of Diving and Hyperbaric Medicine Prince of Wales Hospital, Sydney, NSW 2031,

Australia

1 Leach RM, Rees PJ, Wilmshurst P. ABC of oxygen. Hyperbaric oxygen therapy. BMJ 1998;317:1140-3. (24 October.) 2 Pirone C, Bullock M, Williamson J. Report of 1996 data from the international hyperbaric incident monitoring study (HIMS). Adelaide: Australia Safety Foundation, Royal Adelaide Hospital, 1997.

3 Clark JM. Oxygen toxicity. In: Bennett P, Elliott D, eds. The physiology of medicine and diving. London: WB Saunders, physiology of medi

4 Weslau W, Almeling M. Incidence of oxygen intoxication of the central nervous system in hyperbaric oxygen therapy. In: Marroni A, Oriani G, Wattel F, eds. Proceedings of the international joint meeting of hyperbaric and underwater medicine, Milan. Victoria: Graphica, 1996.

5 Sheffield PJ, Desautels DA. Hyperbaric and hypobaric chamber fires: a 73 year analysis. Undersea and Hyperbaric Medicine 1997;24:153-64.

\section{Authors' reply}

EDITOR-It was not our intention to neglect the value of hyperbaric oxygen therapy in the management of certain tumours. Our article acknowledges the advantages of hyperbaric over normobaric oxygen in promoting angiogenesis and wound healing in irradiated tissue. In particular, we reported the value of preoperative and postoperative hyperbaric oxygen in the prevention of soft tissue radionecrosis and osteonecrosis during treatment of local head and neck tumours requiring local mandibular radiotherapy.

Coles etal comment that combined radiotherapy and hyperbaric oxygen in the management of cancer, although of proved benefit, is not generally in common use. As they report, there are several reasons for this, not least of which are the cost and resource implications and the practical issues of delivering the two treatments simultaneously. They also suggest that available radiotherapy resources are unlikely to be directed towards the use of combined radiotherapy and hyperbaric oxygen in the near future. In our brief article, which was for a non-specialist readership, we did not have enough space to give a detailed cost-benefit analysis or an explanation of why a proved treatment was not used. The lack of resources in radiotherapy and oncology is a problem currently affecting many specialties.

The complication rates for hyperbaric oxygen therapy that we quoted were derived from studies and review articles published during the past 25 years. Complication rates in individual studies primarily depend on the definition of a severe complication, and this is likely to account for some of the variability between studies. Many of the early, small studies quote complication rates higher than those reported in our article. ${ }^{1-4}$ Although recent complication rates are lower, the data from these early studies should not be dismissed. We hope that Trytko and Bennett will publish the data on their complication rates in peer reviewed form.

Finally, although the risk of decompression illness is small and likely to affect only staff breathing air, it still warrants mention in a list of risks of hyperbaric oxygen. Potential 
injuries to staff, as during the small number of associated fires, should be included in a list of risks of the treatment.

Richard Leach Consultant physician

St Thomas's Hospital, London SE1 7EH v.snetkov@umds.ac.uk

Peter Wilmshurst Consultant cardiologist Royal Shrewsbury Hospital, Shrewsbury SY3 8XF

1 Giebfried JW, Lawson W, Biller HF. Complications of hyperbaric oxygen in the treatment of head and neck disease. Otolaryngol Head Neck Surg 1986;94:508-12

2 Ellis ME, Mandal BK. Hyperbaric oxygen treatment: ten years' experience of a regional infectious diseases unit. J Infect Dis 1983;6:17-28.

3 Darke SG, King AM, Slack WK. Gas gangrene and related infection: classification, clinical features and aetiology, management and mortality. A report of 88 cases. Br J Surg 1977;64:104-12

4 Gabb G, Robin ED. Hyperbaric oxygen. A therapy in search of diseases. Risk-benefit analysis in chest medicine. Chest 1987;92:1074-82

\section{Many manoeuvres with yo yos can be dangerous to teeth}

EDIToR-Minerva's dentist's concern for the public health hazards of yo yos is commendable. ${ }^{1}$ To be taken seriously, however, it must be credible. His contention that "walking the dog" is dangerous fails this important test. Tricks such as "skin the cat," "shoot the moon," and "around the world," which require the yo yo to be manoeuvred above shoulder height, are much more likely to break teeth (figure).

In an informal playground survey only two of 57 respondents considered "walking the dog" to be dangerous while "around the world" was overwhelmingly thought to be the most hazardous trick. Indeed, at the school at which this survey was conducted "around the world" has been banned. The severity of potential dental damage will also be influenced by the type of yo yo; those of soft rubber, such as Viper, are safer than

\section{Advice to authors}

We prefer to receive all responses electronically, sent either directly to our website or to the editorial office as email or on a disk. Processing your letter will be delayed unless it arrives in an electronic form.

We are now posting all direct submissions to our website within 72 hours of receipt and our intention is to post all other electronic submissions there as well. All responses will be eligible for publication in the paper journal.

Responses should be under 400 words and relate to articles published in the preceding month. They should include $\leqslant 5$ references, in the Vancouver style, including one to the BMJ article to which they relate. We welcome illustrations.

Please supply each author's current appointment and full address, and a phone or fax number or email address for the corresponding author. We ask authors to declare any competing interest. Please send a stamped addressed envelope if you would like to know whether your letter has been accepted or rejected.

Letters will be edited and may be shortened.

www.bmj.com

letters@bmj.com

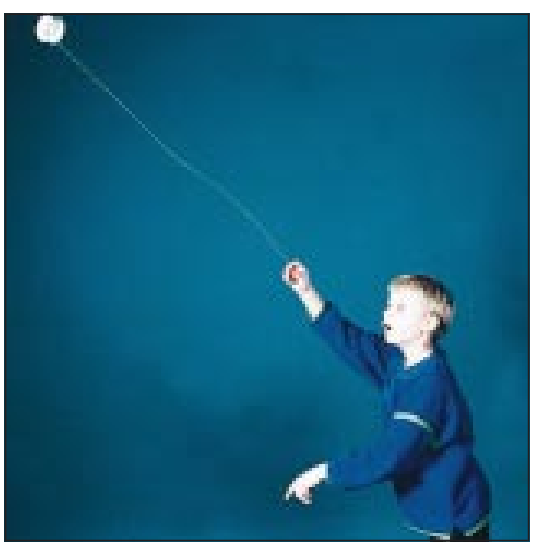

Shooting the moon

hard plastic varieties such as X-Brain and Thunderstone.

We would like to suggest that grown ups shouldn't be such spoilsports.

William Cooper Pupil,year 6

Elizabeth Cooper Pupil,year 4

Nether Green Junior School, Sheffield

Graham Cooper Consultant cardiothoracic surgeon Northern General Hospital, Sheffield S5 7AU

1 Minerva. BMJ 1998;317:1536. (28 November.)

\section{Ingestion of mouthwash by children}

\section{Child proof caps are needed to prevent} deaths

EDITOR-A 3 year old boy was found collapsed and unresponsive at home by his mother. While waiting for the ambulance his mother discovered that a bottle of mouthwash was not in its usual place and she feared that her son had ingested some.

On arrival at the accident and emergency department, the child was comatose (Glasgow coma scale score 3) but breathing on his own, and his oxygen saturation was good. $\mathrm{He}$ was hypothermic (core temperature $34.2^{\circ} \mathrm{C}$ ), and capillary refill time was 3 seconds. A minty odour was detectable on his breath.

Initial blood glucose estimation was $2.1 \mathrm{mmol} / \mathrm{l}$, and he received $3 \mathrm{ml} / \mathrm{kg}$ of $10 \%$ dextrose and $20 \mathrm{ml} / \mathrm{kg}$ of colloid. At $10 \mathrm{~min}$ utes a repeat blood glucose of $2.2 \mathrm{mmol} / \mathrm{l}$ was followed by administration of $2 \mathrm{ml} / \mathrm{kg}$ of $20 \%$ dextrose. Twenty minutes after arrival his blood glucose was $8.7 \mathrm{mmol} / \mathrm{l}$, his coma score was 13 , and capillary refill time was 3 seconds. He received another bolus of $20 \mathrm{ml} /$ $\mathrm{kg}$ of colloid, and by 30 minutes after arrival he was awake and alert.

Initial arterial blood gas measurements indicated a marked metabolic acidosis $(\mathrm{pH}$ 7.19 , base excess $16 \mathrm{mmol} / \mathrm{l})$. His initia serum alcohol concentration was 101 $\mathrm{mg} / \mathrm{dl}$. By 10 hours after admission his blood glucose was stable and the acidosis had resolved. He made a full recovery.

The mouthwash that he had ingested was a supermarket "extra strength" own brand which contains $37 \%$ alcohol. It is supplied in a $500 \mathrm{ml}$ container without a child proof cap. The child's parents were unaware that there was any danger associated with the ingestion of mouthwash.

In a recent survey of poisonings in children under age $6,12.5 \%$ were found to be due to "cosmetics, personal-care products or alcohol-containing products" including mouthwashes. ${ }^{1}$ Of the poisonings involving products containing alcohol, $97 \%$ were not beverages but other substances, which included perfumes and mouthwash.

Mouthwashes, unlike perfumes, are usually highly palatable, brightly coloured, and readily available to young children. Manufacturers are not required to use child proof containers or specify the alcohol content.

A review of the literature identified seven other case reports worldwide of acute coma secondary to mouthwash ingestion in children. Of these, five had documented evidence of hypoglycaemia before treatment. Two children died despite resuscitation efforts.

There have been calls for more stringent safety controls for mouthwashes since the first case report 19 years ago but no legislative action has been taken. Child proof containers and larger, more specific warning labels are urgently needed and could prevent the deaths of children.

Tamsin Wade Paediatric registrar

Alison Gammon Consultant in accident and emergency medicine

Stoke Mandeville Hospital, Aylesbury, Buckinghamshire HP21 8AI

1 Litovitz T, Manoguerra A. Comparison of pediatric poisoning hazards: an analysis of 3.8 million exposure incidents. Pediatrics 1992/89:999-1006.

\section{Industry reply}

EDITOR-Thank you for bringing to our attention the recent case of a young child who required hospital attention after apparently ingesting a mouthwash that contained alcohol. Alcohol serves a number of functions in a mouthwash including assisting in the cleaning action, adding to antibacterial activity, and dispersing ingredients. However, alcohol free mouthwashes are readily available to provide choices for consumers.

Although hospitalisation after accidental ingestion of oral hygiene products is comparatively uncommon, the industry has reviewed the issue in detail. Where appropriate, the manufacturers of mouthwashes have introduced measures to further reduce the likelihood of accidental ingestion, including the incorporation of child resistant closures and the use of warning statements such as "keep out of reach of children" and "not suitable for use by children under 6 years of age."

In the light of this specific case the industry will again review these measures to determine whether further action is necessary.

Marion Kelly Director genera

Cosmetic Toiletry and Perfumery Association, Josaron House, London W1M 9HD

\section{Rapid responses $\quad$ B Rapid responses submitted directly to our website are available on www.bmj.com}

